\title{
To drip or to mothership - the ongoing race for stroke thrombectomy
}

\author{
Michał Karliński \\ $2^{\text {nd }}$ Department of Neurology, Institute of Psychiatry and Neurology, Warsaw, Poland
}

Key words: acute stroke, mothership, drip-and-ship, thrombolysis, mechanical thrombectomy

(Neurol Neurochir Pol 2021; 55 (5): 416-417)

Modern acute stroke care is firmly oriented on reperfusion therapies. In Europe, intravenous thrombolysis (IVT) has been the gold standard of care for almost 20 years. Several years ago, this standard was augmented by the introduction of evidence-based mechanical thrombectomy (MT) for patients with large vessel occlusion (LVO). The pace of implementation of MT depends on the financial and organisational capabilities of particular healthcare systems, and thus varies across the continent [1-4].

Both IVT and MT are highly time-sensitive, and this remains true even in the era of late window thrombectomy. Delays in delivering endovascular thrombectomy to stroke patients can result in lower recanalisation rates and definitely results in substantial loss of healthy life-years $[5,6]$.

This is why door-to-needle time and door-to-groin puncture time have joined the simple rate of treated patients as the key performance indicators of each stroke unit [1-4]. The necessary struggle for optimisation of logistics exerts additional pressure on the whole system. For an acute stroke patient, the first critical point in the medical pathway is to raise among the ambulance crews a suspicion of stroke that (i) will turn out to be a stroke that (ii) qualifies for reperfusion therapy [7]. The next critical point is to transfer the patient to the right hospital. Given the organisational requirements, costs and the availability of properly trained personnel, MT is delivered only in comprehensive stroke centres (CSC), whilst all stroke units are able to administer IVT. This discrepancy results in two distinct treatment paradigms.

The default model, widely known as 'drip-and-ship' (DAS), implies that all patients with suspected acute stroke are transferred to the nearest stroke-ready hospital (i) to identify whether they are eligible for IVT or MT based on their history, clinical presentation, brain and vessel imaging; (ii) to initiate IVT; and (iii) to transfer to the cooperating CSC for MT.

The second model, commonly known as 'mothership' (MS), implies selection of patients with a high probability of acute ischaemic stroke caused by LVO at the scene, followed by a direct transfer to the CSC, thus bypassing the nearest strokeready hospital. Such patients may benefit from (i) earlier MT and (ii) shorter in-hospital delays to IVT. However, this is at the costs of (i) possibly overloading CSCs with patients not suitable for MT; (ii) the risk of not giving IVT to patients who would still be within the therapeutic window at their nearest hospital; and (iii) the consumption of additional resources from the ambulance service. The evidence overall points in favour of MS, but it is derived mostly from observational studies and does not refer to a uniform triage paradigm [8-12]

In this issue of Neurologia i Neurochirurgia Polska, Luchowski et al. attempt to answer the question of whether the MS pathway might be superior in patients suffering from acute stroke in the Polish healthcare system [13]. This is a retrospective analysis of 400 consecutive patients admitted for MT to a single CSC located in Lublin, Poland that coordinates a regional stroke network of 12 stroke units. The MS group ( $\mathrm{n}=$ $267,67 \%)$ and the DAS group $(\mathrm{n}=133,33 \%)$ were balanced in terms of basic demographic factors, comorbidities and stroke severity. Patients delivered in the MS model had a significantly shorter time form onset to groin puncture (179 $\mathrm{min} v \mathrm{~s}$. $264 \mathrm{~min}$ ) and a shorter time from picture to puncture $(62 \mathrm{~min}$ vs. $146 \mathrm{~min}$ ) at the cost of a longer time from door to groin ( $86 \mathrm{~min} v s .35 \mathrm{~min}$ ). There were no significant differences in terms of successful recanalisation (TICI 2b-3), symptomatic intracranial haemorrhages, NIHSS at discharge from CSC, 3 -month mortality, or functional independence ( $m R S ~ 0-2$ ).

Address for correspondence: Michał Karliński, Institute of Psychiatry and Neurology, Sobieskiego 9 Str., 02-957 Warsaw, Poland; e-mail: mkarlinski@ipin.edu.pl Received: 13.09.2021 Accepted: 1.10.2021 Early publication date: 12.10 .2021

This article is available in open access under Creative Common Attribution-Non-Commercial-No Derivatives 4.0 International (CC BY-NC-ND 4.0) license, allowing to download articles and share them with others as long as they credit the authors and the publisher, but without permission to change them in any way or use them commercially. 
However, the authors observed a statistically significant and clinically relevant difference favouring MS (33\% vs. $23 \%)$ in terms of excellent functional outcome (mRS 0-1).

Luchowski et al.'s study does not resolve the question of whether to 'drip' or to 'mothership'. One should note that the presented results reflect a scenario in which all patients transferred in the MS model actually undergo MT, and in which the primary stroke centres have long 'door-in doorout' times. The only large randomised clinical trial, carried out in Catalonia in Spain, failed to prove the superiority of the MS model in terms of clinical outcome partly because of the very good efficiency of the primary hospitals and partly because the proportion of patients undergoing MT was $50 \%$ (compared to $41 \%$ in DAS) at the cost of $20 \%$ relative reduction of IVT rate (RACECAT, presented at ESOC 2020, not yet published). However, the study by Luchowski et al. adds to the ongoing discussion another important piece of evidence in favour of the MS model. Noteworthy, the Polish healthcare system can be briefly described as developed but modestly financed and suboptimally organised, which slowed the widespread implementation of MT [14]. Therefore, the results may be usefully extrapolated to other countries in Central and Eastern Europe.

It the context of other studies, it seems important to underline that 'one size does not fit all'. The decision whether to implement a particular stroke system should depend not only on the general evidence. It should also be tailored for particular regions, depending on their geography and the capabilities of their stroke services, including the challenges around interhospital transfers and prenotification.

Conflict of interest: None.

\section{References}

1. Błażejewska-Hyżorek B, Czernuszenko A, Członkowska A, et al. Wytyczne postępowania w udarze mózgu. Polski Przegląd Neurologiczny. 2019; 15(A): 1-156, doi: 10.5603/ppn.2019.0001.

2. Powers W, Rabinstein A, Ackerson T, et al. et al.. Guidelines for the Early Management of Patients with Acute Ischemic Stroke. 2019; 50: e344-418.

3. Turc G, Bhogal P, Fischer U, et al. European Stroke Organisation (ESO) - European Society for Minimally Invasive Neurological Therapy (ESMINT) Guidelines on Mechanical Thrombectomy in Acute Ischaemic StrokeEndorsed by Stroke Alliance for Europe (SAFE). Eur Stroke J. 2019; 4(1): 6-12, doi: 10.1177/2396987319832140, indexed in Pubmed: 31165090.
4. Berge E, Whiteley W, Audebert H, et al. De, Fonseca AC, Padiglioni C, European Stroke Organisation (ESO) guidelines on intravenous thrombolysis for acute ischaemic stroke. ; 2021: 6I-LXII.

5. Nowak K, Derbisz J, Jagieła J, et al. Time from stroke onset to groin puncture affects rate of recanalisation after mechanical thrombectomy: a real-life single centre experience. Neurol Neurochir Pol. 2020; 54(2): 156-160, doi: 10.5603/PJNNS.a2020.0024, indexed in Pubmed: 32242914.

6. Almekhlafi MA, Goyal M, Dippel DWJ, et al. HERMES Trialists Collaboration. Healthy Life-Year Costs of Treatment Speed From Arrival to Endovascular Thrombectomy in Patients With Ischemic Stroke: A Meta-analysis of Individual Patient Data From 7 Randomized Clinical Trials. JAMA Neurol. 2021; 78(6): 709-717, doi: 10.1001/jamaneurol.2021.1055, indexed in Pubmed: 33938914.

7. Kozera-Strzelińska D, Karliński M, Rak G, et al. Stroke and TIA mimics in patients referred to a neurological emergency department by non-ambulance physicians, ambulance physicians and paramedics. Neurol Neurochir Pol. 2019; 53(1): 83-89, doi: 10.5603/PJNNS. a2019.0002, indexed in Pubmed: 30614515.

8. Romoli M, Paciaroni M, Tsivgoulis G, et al. Mothership versus Drip-andShip Model for Mechanical Thrombectomy in Acute Stroke: A Systematic Review and Meta-Analysis for Clinical and Radiological Outcomes. J Stroke. 2020; 22(3): 317-323, doi: 10.5853/jos.2020.01767, indexed in Pubmed: 33053947.

9. Schlemm L, Endres M, Scheitz JF, et al. Comparative Evaluation of 10 Prehospital Triage Strategy Paradigms for Patients With Suspected Acute Ischemic Stroke. J Am Heart Assoc. 2019; 8(12): e012665, doi: 10.1161/JAHA.119.012665, indexed in Pubmed: 31189395.

10. Cabal M, Machova L, Vaclavik D, et al. New Prehospital Triage for Stroke Patients Significantly Reduces Transport Time of EVT Patients Without Delaying IVT. Front Neurol. 2021; 12: 676126, doi: 10.3389/ fneur.2021.676126, indexed in Pubmed: 34220685.

11. Xu Y, Parikh N, Jiao B, et al. Decision Analysis Model for Prehospital Triage of Patients With Acute Stroke. Stroke. 2019; 50(4): 970-977, doi: 10.1161/strokeaha.118.023272.

12. Holodinsky JK, Patel AB, Thornton J, et al. Drip and ship versus direct to endovascular thrombectomy: The impact of treatment times on transport decision-making. Eur Stroke J. 2018; 3(2): 126-135, doi: 10.1177/2396987318759362, indexed in Pubmed: 31008345.

13. Luchowski P, Wojczal J, Prus K, et al. Direct admission vs. secondary transfer for mechanical thrombectomy: long-term clinical outcomes from a single Polish Comprehensive Stroke Centre. Neurol Neurochir Pol. 2021 [Epub ahead of print], doi: 10.5603/PJNNS. a2021.0050, indexed in Pubmed: 34346053.

14. Słowik A, Wnuk M, Brzegowy P, et al. Polish Thrombectomy Initiative. Mechanical thrombectomy in acute stroke - Five years of experience in Poland. Neurol Neurochir Pol. 2017; 51(5): 339-346, doi: 10.1016/j.pjnns.2017.05.004, indexed in Pubmed: 28756015. 